\title{
Choroid Tissue Supports the Survival of Ciliary Ganglion Neurons in vitro
}

\author{
Lisa A. F. Wentzek, Chauncey W. Bowers, ${ }^{a}$ Lamia Khairallah, and Guillermo Pilar \\ Physiology and Neurobiology Department, The University of Connecticut, Storrs, Connecticut 06269-3042
}

It is well established that during in vivo development the neurons of the avian ciliary ganglion are dependent for their survival on structures in the eye. Separate neuron populations innervate intraocular smooth and striated muscle targets. All ciliary neurons survive when cocultured with striated muscle. We demonstrate that when ciliary ganglion neurons are plated on explants of the choroid coat (a smooth muscle-containing target tissue) using a defined medium (N2), the neurons survive and grow vigorously into the tissue, forming contacts between axons and target cells identified as smooth muscle. Conditioned medium from choroid explants also rescues all the neurons, as does coculturing ciliary ganglion neurons with dissociated choroid cells. However, the presence of horse serum and chick embryo extract in the medium inhibits the choroid's ability to support ciliary neurons. The effects of these additives on the phenotypic expression of the smooth muscle may explain the inability of previous investigators to demonstrate target-derived support from smooth muscle preparations. Because the choroid contains cell types other than smooth muscle (e.g., fibroblasts and endothelial cells), we could not identify smooth muscle as the only cell type responsible for the release of the soluble trophic factor present in the target tissue. However, indirect evidence using avian primary fibroblast cultures, a fibroblast cell line, and an anatomically simple smooth muscle preparation, the avian amnion, suggests that smooth muscle cells are sufficient to account for the observed trophic activity, and that similar target-derived molecules support the survival of both types of ciliary ganglion cells.

[Key words: trophic factors, neuron survival, ciliary ganglion, choroid coat, smooth muscle, target tissue]

The developing PNS normally undergoes a period of cell death, the extent of which depends on the availability of the target tissues (Hamburger and Oppenheim, 1982; Cowan et al., 1984). In the avian ciliary ganglion (CG) evidence suggests that the neurons compete for trophic support from their targets during the cell death period (Pilar et al., 1980; for recent review, Pilar

\footnotetext{
Received June 18, 1992; revised Jan. 29, 1993; accepted Feb. 8, 1993.

We are grateful to Dr. E. D. Oliva for his participation in the initial experiments We thank Drs. L. Landmesser, D. B. Gray, J. Covault, and L. Dahm for many helpful discussions and experimental suggestions, and Mr. L. Cupceancu for his photographic assistance. This work was supported by NIH NS10330, NIH Training Grant NS07324-05, and the University of Connecticut Research Foundation. L.A.F.W. is a National Consortium for Educational Access (NCEA) Fellow.

Correspondence should be addressed to Dr. Guillermo Pilar, The University of Connecticut, Department of Physiology and Neurobiology, 75 North Eagleville Road, U-42, Storrs, CT 06269-3042.

apresent address: Division of Neuroscience, Beckman Research Institute of the City of Hope, 1450 East Duarte Road, Duarte, CA 91010.

Copyright (C) 1993 Society for Neuroscience $0270-6474 / 93 / 133143-12 \$ 05.00 / 0$
}

et al., 1988). The exact nature, source, and specificity of the trophic factor(s) are of interest because the neurons of the $C G$ are approximately equally divided into two distinct populations that innervate two different types of muscle targets: ciliary neurons that innervate striated muscle (iris and ciliary body) and choroid neurons that innervate smooth muscle (blood vessels in the choroidal coat of the eye) (Marwitt et al., 1971; Landmesser and Pilar, 1974; Meriney and Pilar, 1987). Both of these neuron populations exhibit about $50 \%$ cell death around the time of synaptogenesis in their target tissues (Landmesser and Pilar, 1974; Meriney et al., 1987). Although in vitro techniques have established that striated muscle from non-eye sources (e.g., skeletal muscle) provides a factor or factors that support both populations of neurons in dissociated cell culture (Bennett and Nurcombe, 1979; Nishi and Berg, 1979; Creedon and Tuttle, 1988), attempts to demonstrate trophic support by smooth muscle, including the choroid itself, have failed (Creedon and Tuttle, 1988). Because of the anatomical location of the choroid coat of the eye, the choroid cannot be specifically removed in ovo to determine the effect of this target on the neurons that innervate it. Thus, Creedon and Tuttle's work provides the only data that specifically addresses the developmental relationship between choroid neurons and their target. It is significant, therefore, that their data challenged the widely held postulate that neurons depend on their targets for survival. The present work demonstrates that choroid explants, dissociated cells from the choroid, and choroid-conditioned medium (CCM) all are capable of providing a factor that promotes survival of $\mathrm{CG}$ neurons in vitro. Furthermore, our finding that the conditioned medium from a simple smooth muscle preparation (the avian amnion) also promotes the survival of CG neurons suggests that the factor necessary for survival is probably supplied by smooth muscle. Finally, with extensive electron microscopy (EM) studies, we attempt to define the nature of the anatomical interaction between the surviving neurons and their target tissues.

An abstract partially describing these results was presented elsewhere (Wentzek et al., 1989).

\section{Materials and Methods \\ Cell culture}

Neurons. Dissections were done in oxygenated Tyrodes (in mM): 134 $\mathrm{NaCl}, 3 \mathrm{KCl}, 3 \mathrm{CaCl}_{2}, 1 \mathrm{MgCl}_{2}, 12$ glucose, $20 \mathrm{NaH}_{2} \mathrm{CO}_{3}, \mathrm{pH} \mathrm{7.2,} \mathrm{with}$ a dash of phenol red. Unless noted otherwise, cultures were grown in the chemically defined (N2) medium of Bottenstein (1983). This medium is Dulbecco's Modified Eagle's Medium (DMEM) and Ham's Nutrient Mixture (F12) (1:1; Sigma) with added (final concentrations) sodium bicarbonate (15 mM), sodium selenite (30 nM), putrescine (100 $\mu \mathrm{M})$, progesterone $(20 \mathrm{mM})$, insulin $(5 \mathrm{mg} / \mathrm{ml})$, and conalbumin $(40 \mathrm{mg} /$ $\mathrm{ml})$. Also included were glutamine $(1 \mathrm{~mm})$, pyruvate $(1 \mathrm{~mm})$, penicillin $(100 \mu / \mathrm{ml})$, and streptomycin sulfate $(0.1 \mathrm{mg} / \mathrm{ml})$. Cultures were fed 
every 2-3 d by replacing half of the dish or well volume with fresh medium. Ciliary ganglia were removed from embryonic stage (St) 3435 (Hamburger and Hamilton, 1951) chick embryos by exposing the lateral side of the optic nerve near the posterior portion of the sclera. Ganglia were dissociated by incubation in $0.08 \%$ trypsin in $\mathrm{Ca}^{2+}$ - and $\mathrm{Mg}^{2+}$-free Tyrodes at $4^{\circ} \mathrm{C}$ for $5 \mathrm{~min}$ before switching to $37^{\circ} \mathrm{C}$ for 25 min. The trypsin was removed and inhibited by three washes with DMEM:F1 2 containing $10 \%$ heat-inactivated horse serum. The ganglia were then mechanically dissociated by trituration with pipettes of diminishing bore. The final suspension of cells was centrifuged at $100 \times$ $g$ and resuspended in N2 medium. Dissociated CG cells were plated on poly-DL-ornithine (P-Orn)-coated plastic, P-Orn-coated Aclar coverslips, or choroidal tissue. Neurons on P-Orn were plated with a $50-100$ $\mu \mathrm{l}$ drop of $\mathrm{N} 2$ (containing $0.5-1.0$ ganglion) and incubated at $37^{\circ} \mathrm{C}$ for 1-2 hr. One milliliter of the indicated medium was then added. The number of neurons per well was estimated by counting the neurons in a field at the center of the original drop and then counting four more fields adjacent to the first. Phase-bright cells, as well as round, gray cells with well-defined nuclei and nucleoli (and usually a process), were counted. The latter class of cell was clearly neuronal since examples were followed in culture and observed to become phase bright and elaborate long, thin processes. Independent counts by two different investigators gave the same results for each well within $10 \%$. Initial plating densities from these counts were approximately 8000 neurons $/ \mathrm{cm}^{2}$.

Choroid explant and choroid dissociated cells. Choroid coats from chick embryo eyes (St 41-42) were exposed by hemisection of the eye around the limbus and removal of the vitreous humor and lens. $\Lambda$ fter the choroid fissure and retina were excised (see Creedon and Tuttle, 1988), the choroid was cleaned of pigmented epithelium by gentle scraping with a small piece of cotton and separated from the sclera. These choroid sheets were either cultured intact or dissociated and plated in rat tail collagen-coated plastic wells. The choroids were dissociated by treatment with $0.3 \%$ collagenase for $1.5 \mathrm{hr}$ at $37^{\circ} \mathrm{C}, 0.08 \%$ trypsin for $10 \mathrm{~min}$ at $37^{\circ} \mathrm{C}$, and trituration (Creedon and Tuttle, 1988). The dissociated choroid cells were plated and allowed to grow to confluence in either DMEM:F12 with 10\% fetal bovine serum (FBS) or DMEM:F12 with $5 \%$ chick embryo extract (CEE) and $10 \%$ horse serum over a period of about $5 \mathrm{~d}$. When dissociated ciliary neurons $\left(4000-6000 / \mathrm{cm}^{2}\right)$ were added to the confluent choroid carpet, the medium was changed to either $\mathrm{N} 2$ alone or $\mathrm{N} 2$ with $10 \%$ horse serum. For coculture experiments, the medium was changed to $\mathrm{N} 2$ at least $24 \mathrm{hr}$ bcforc plating the ncurons.

Primary cultures of chick fibroblasts. Fibroblast cultures were prepared using skin from the scalp of two St 37 chick embryos. The tissue was minced, and incubated in $0.04 \%$ trypsin for $20 \mathrm{~min}$ before mechanical trituration. The cellular suspension was plated on untreated plastic at an approximate density of $7 \times 10^{4}$ cells $/ 60 \mathrm{~mm}^{2}$ petri dish in an enriched medium of $\mathrm{N} 2,10 \%$ FBS, and $2 \%$ chicken serum. After $24 \mathrm{hr}$, the plates were gently washed with medium and fresh medium was added. When the cells covered the surface of the dish, the cells were incubated in $0.04 \%$ trypsin for 5-10 min and then resuspended. The cells were centrifuged ( $2000 \mathrm{rpm}$ for $5 \mathrm{~min})$ and replated at a density of $7 \times 10^{4}$ cells/ dish. The cultures were passed three to eight times before being used as a substrate for neurons. At the last passage, the fibroblasts were plated on collagen-coated plastic plates. Twenty-four to $36 \mathrm{hr}$ before seeding the CG neurons, the fibroblast culture medium was replaced by $\mathrm{N} 2$ medium. The following day, the fibroblast-"conditioned" medium was removed from the dishes and replaced with fresh N2. Dissociated CG neurons were plated at a density of $6 \times 10^{3} \mathrm{cells} / \mathrm{cm}^{2}$ on fibroblast cultures or in wells containing fibroblast-conditioned medium. Neuron survival was determined in neuron-fibroblast cocultures in N2 medium, $\mathrm{N} 2$ medium and $1.5 \%$ CIPE (defined below), or in fibroblast-conditioned medium.

$3 T 3$ fibroblast cell line. An intact, confluent monolayer of cells from the mouse fibroblast cell line 3T3 was used as a substrate upon which CG neurons were plated. The $3 \mathrm{~T} 3$ cells were allowed to grow to confluence in $\mathrm{N} 2$ containing $10 \%$ FBS. On the day the neurons were plated, the FBS was removed by rinsing the fibroblasts with N2 without FBS. Parallel cultures were prepared; one set of wells contained an extract of choroid, iris (and ciliary body), and pigment epithelium (CIPE); the other did not. Neurons were counted under phase optics at 2 and $5 \mathrm{~d}$.

\section{Cocultures of dissociated neurons with intact choroid explants}

Choroids were removed as described above and pinned to Sylgardcoated $35 \mathrm{~mm}$ plastic petri dishes containing $3 \mathrm{ml}$ of $\mathrm{N} 2$ medium, one or two choroids per dish. For most of the experiments, most of the pigmented epithelium was removed while in some experiments little attempt was made to remove it. In the former case, no more than $5 \%$ of the area of the choroid was still covered with pigment. After the choroids were in culture for $24 \mathrm{hr}$, freshly dissociated neurons were plated onto $1 \mathrm{~cm}^{2}$ pieces of P-Orn-coated Aclar and incubated for $1-2$ $\mathrm{hr}$ in N2 in separate wells. The pieces of Aclar were then transferred to dishes containing intact choroids. In other experiments, the neurons were seeded directly on top of the choroid sheets.

\section{Preparation of conditioned medium and eye extracts}

Chick embryo extract (CEE) was prepared according to published methods (Paul, 1970), as were the extracts from various eye tissues (Manthorpe et al., 1980). Briefly, the different eye extracts were obtained by tissue homogenization at $4^{\circ} \mathrm{C}$ in distilled water $(0.5 \mathrm{ml} / \mathrm{eye})$ and subsequent addition of $1 \mathrm{M}$ sodium phosphate buffer $(1 \mathrm{ml}$ in $100 \mathrm{ml}$ of extract) at $\mathrm{pH} 7.0$. The homogenate was then centrifuged for $70 \mathrm{~min}$ at $32,000 \mathrm{rpm}$ and the supernatant passed through a $0.22 \mu \mathrm{m}$ filter. Choroid-conditioned medium (CCM) was prepared from St $41-42$ choroids that were pinned flat in $35 \mathrm{~mm}$ Sylgard-coated petri dishes ( 2 choroids/ dish), as described above. Each coat weighed 6-8 mg and, in its flattened state, had a total surface area of approximately $1.5 \mathrm{~cm}^{2}$. Approximately $3 \mathrm{ml}$ of $\mathrm{N} 2$ medium was added to the dishes and the conditioned medium was collected 2-3 d later. The CCM was subsequently decanted and either used fresh or stored at $-70^{\circ} \mathrm{C}$ until use. for some experiments the CCM was diluted 1:1 v/v with fresh $\mathrm{N} 2$, while for others it was centrifuged at $32,000 \mathrm{rpm}$ for $70 \mathrm{~min}$ or concentrated using Centricon centrifugal microconcentrators (Amicon). Amicon centrifuge microconcentrators of $10 \mathrm{kDa}$ molecular weight cutoff were used to concentrate the CCM. Because we were concerned that concentrating the medium would concentrate metabolic byproducts as well as the factor(s) of interest, we prepared a $10 \times$ concentrate of conditioned medium and diluted it 1:1 with fresh N2 medium. To verify that none of the activity was lost to the filtrate, we tested the survival activity of the filtrate $(<10$ $\mathrm{kDa}$ molecular weight) and found that it did not contain any survival activity (data not shown).

\section{Microscopy}

Immunolabeling. A mouse monoclonal antibody (C2) against a neurofilament antigen was used to visualize neurons and their processes (Dahm and Landmesser, 1988). Cultures were fixed for $2 \mathrm{~min}$ at $-20^{\circ} \mathrm{C}$ with acetone, and then incubated in the $\mathrm{C} 2$ hybridoma supernatant diluted 1:2 with PBS ( $20 \mathrm{~mm}$ sodium phosphate $\mathrm{pH} 8.0,0.9 \% \mathrm{NaCl}$ ) and $0.9 \%$ Triton-X $100(0.23 \%$ Triton, final) for $2 \mathrm{hr}$ at room temp. The tissue was then further fixed for $25 \mathrm{~min}$ with $4 \%$ paraformaldehyde in PBS and incubated with a fuorescein-coupled goat anti-mouse IgG (Sigma) diluted 1:50 in PBS and 2\% bovine serum albumin for $3.5 \mathrm{hr}$ at room temp. The preparations were observed and photographed under epifluorescent illumination using a Nikon Microphot-FX microscope.

Transmission EM. Tissue for transmission EM (TEM) was fixed with $1.5 \%$ glutaraldehyde, $1.5 \%$ paraformaldehyde, and $1.5 \%$ acrolein in 0.1 M sodium cacodylate, $\mathrm{pH} 7.2$, at $4^{\circ} \mathrm{C}$ for $3 \mathrm{hr}$. For choroid explants, thc tissue was osmicated $1 \mathrm{hr}$ with $2 \% \mathrm{OsO}_{4}$ in $0.1 \mathrm{M}$ sodium cacodylate, washed with distilled water, dehydrated through ascending series of ethanol to propylene oxide, and embedded in Epon-Araldite. Thin sections were cut on an LKB Ultratome III, mounted on uncoated grids, sequentially stained with uranyl acetate and lead citrate, and viewed with a Philips 300 EM. Dissociated choroid cultures were fixed, osmicated, and dehydrated directly on Aclar coverslips before embedding in a thin layer of Epon-Araldite. After polymerization, the Aclar was peeled away and the cultures were viewed under an inverted microscope. Selected regions were cut out of the sheet of resin and subsequently reembedded in Epon-Araldite. The blocks were sectioned, mounted, and stained as usual.

\section{Labeling of ciliary neurons}

We selectively back-labeled one population of neurons in the ganglion with the lipophilic fluorescent dye DiI (1,1'-dioctadecyl-3,3,3',3'-tetramethylindocarbocyanine perchlorate) (Honig and Hume, 1986). We labeled the ciliary neurons because these nerves exit the ganglion through a large main trunk and arc casicr to inject than the smaller, finer fibers of the choroid nerves. The procedure was performed on intact isolated ciliary ganglia, superfused with oxygenated Tyrodes at $35^{\circ} \mathrm{C}$ as follows: St 34 ciliary ganglia were dissected out and the ciliary nerves were exposed. The ganglia were left attached to a small wedge of sclera con- 

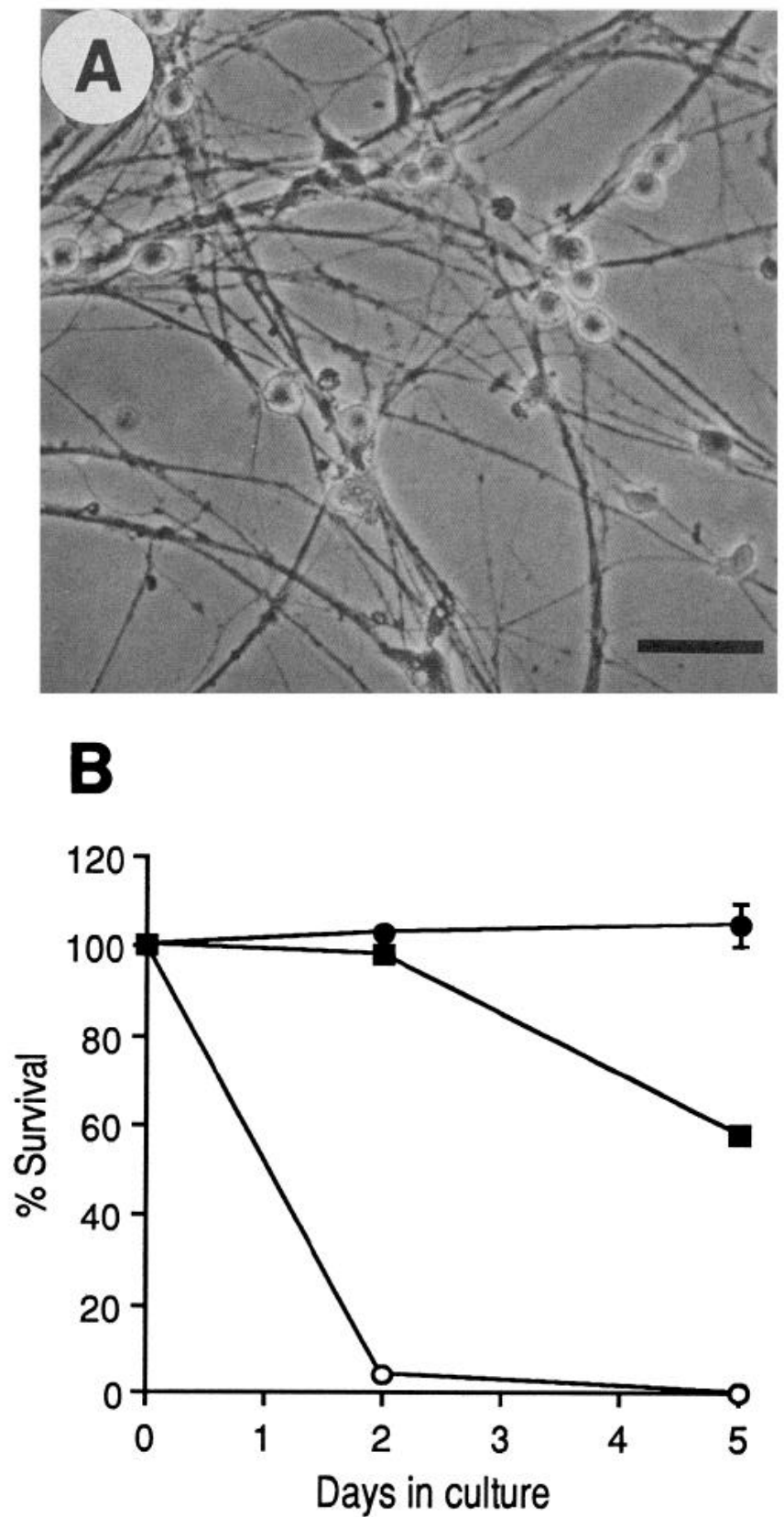

Figure 1. Survival of dissociated CG in defined medium (N2). $A$, Phase-contrast micrograph of neurons from St 34 dissociated CG cultured $5 \mathrm{~d}$ in N2 media with $1.5 \%$ CIPE. Scale bar, $100 \mu \mathrm{m}$. $B$, Neuronal survival in N2 (open circles), N2 plus $1.5 \%$ CIPE extract (solid circles), or N2 plus $0.3 \%$ CIPE extract (solid squares) after $5.5 \mathrm{~d}$ in culture. $n=$ 3 or 4. Data in this figure, as in Figures $4,5,12$, and 13, are mean \pm SE.

taining the choroid nerves for ease of handling and postinjection examination (see below). DiI ( $3 \mathrm{mg} / \mathrm{ml}$ in $100 \%$ ethanol) was pressure injected from a glass micropipette inserted into the trunk of the ciliary nerve 1-2 $\mathrm{mm}$ from the body of the ganglion. After allowing up to 12 $\mathrm{hr}$ for the dye to diffuse back to the ciliary neuronal somata, the ganglia were removed and the scleral wedges were examined under a rhodamine filter for retrograde label of the ciliary nerves and the absence of dye in the choroid nerves. Successfully injected ganglia were dissociated and plated at a density of 0.5 ganglion/well in P-Orn-treated 24-well plastic tissue culture dishes. To determine the ratio of labeled to nonlabeled neurons at initial plating, five $1 \mathrm{~mm} \times 1 \mathrm{~mm}$ fields in each well were alternately observed under phase-contrast optics and epifluorescent illumination using a rhodamine filter. Cells were counted at plating and after 2 and $5 \mathrm{~d}$ of culture. Choroid neuron (plus unlabeled ciliary neu-
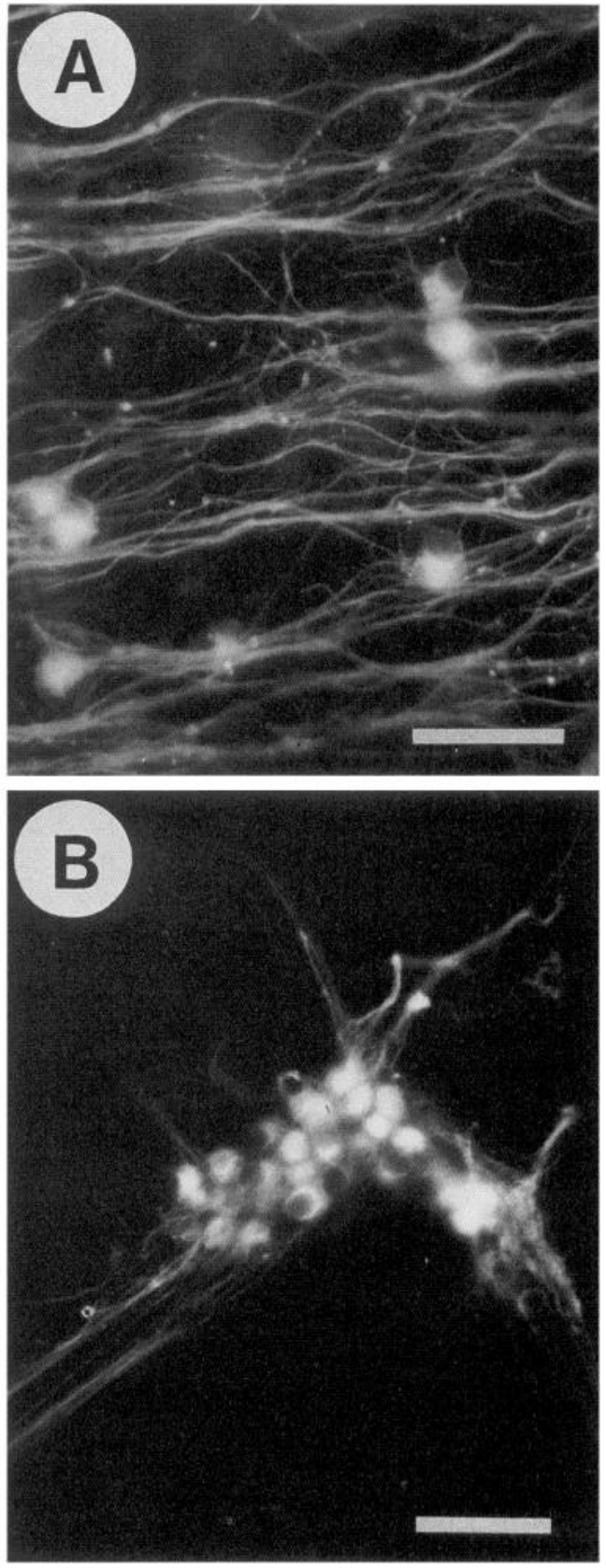

Figure 2. Dissociated ciliary neurons cultured on intact choroids (explants). Neurons were visualized using an antibody against a neurofilament antibody (C2). A, After $2.5 \mathrm{~d}$ in culture, neuronal cell bodies are randomly distributed on the surface of the choroid. Note that the processes grow in a nonfasciculated parallel pattern. $B$, After $5 \mathrm{~d}$ in culture the formerly scattered neuronal somata have clustered and axons have fasciculated. Scale bars, $50 \mu \mathrm{m}$.

rons) counts were taken as the difference between total cells (counted under phase optics) and labeled cells (ciliary neurons).

\section{Results}

\section{Culture conditions}

Cells were cultured in a defined medium (N2) with additives, as noted. Dissociated neurons from St $34 \mathrm{CG}$ attached to the P-Orn-coated surface of the tissue culture wells. When CIPE, an extract of the intraocular muscle targets of the ganglion, was added to the basic medium $(1.5 \% \mathrm{v} / \mathrm{v})$, the neurons extended processes and survived for over a week (Fig. 1A: phase-contrast 

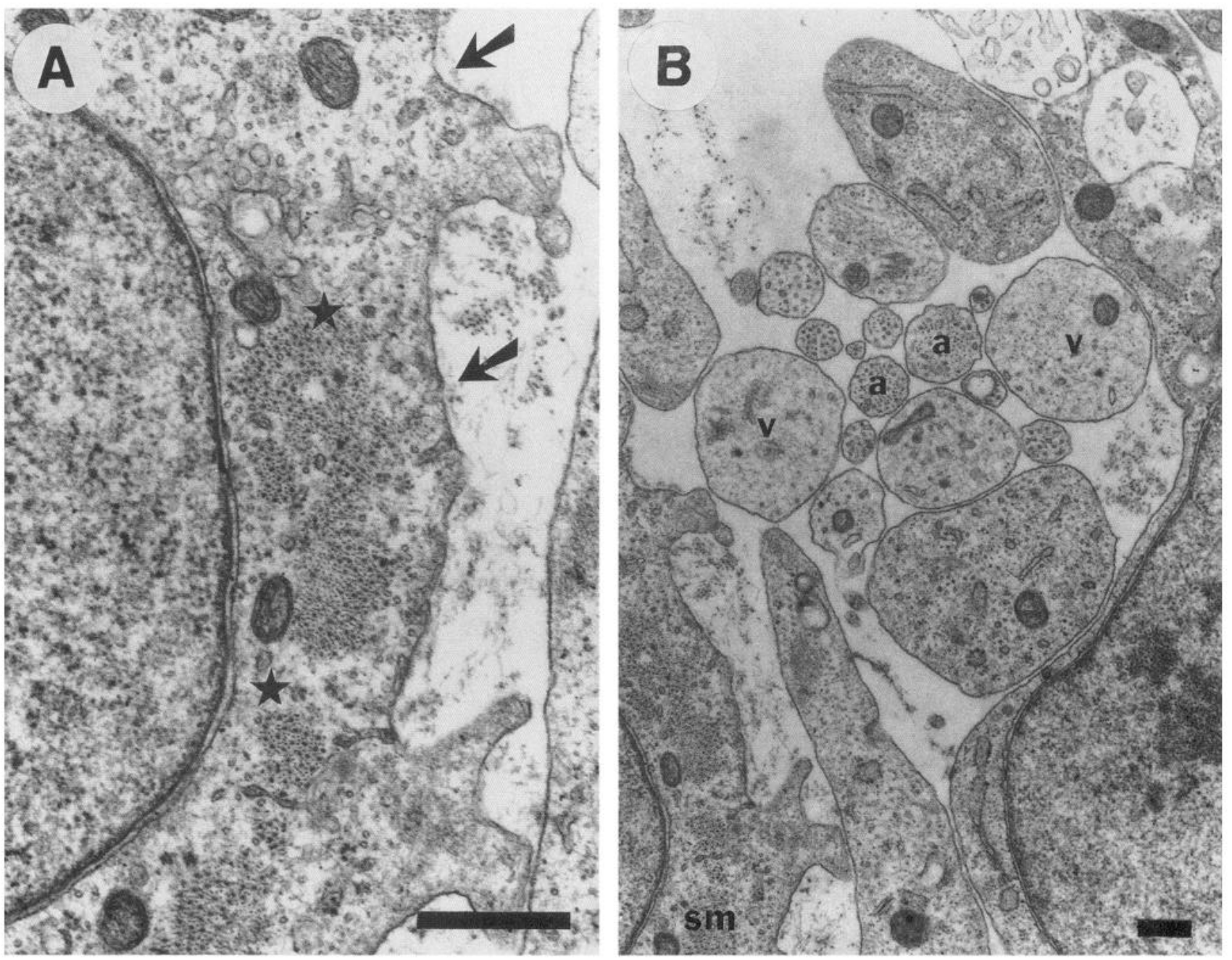

Figure 3. Transmission electron micrographs of neuron-choroid explant coculture showing ultrastructural characteristics of the tissues after $5 \mathrm{~d}$ in vitro (N2 medium). A, Myofilament-containing cell identified as a smooth muscle cell: cross section of choroid explant. Thin and thick filaments in cross section are clearly recognized and are mixed on most of the figures, but there are areas of only thin filaments (stars). Arrows label the basal lamina, and the second arrow from the top also marks a caveola. These are all characteristic of smooth muscle cells in culture. $B$, The same area as $A$ is shown at lower power. The smooth muscle $(\mathrm{sm})$, in the lower left part of the figure, shows the growing axons $(a)$ and varicosities $(v)$ close to the smooth muscle cells (sm). Scale bars, $0.5 \mu \mathrm{m}$.

image of 5-d-old culture; Fig. 1B, solid circles: counts of the same cultures over a $5 \mathrm{~d}$ period). Consistent with previous studies (Skaper et al., 1984), these neurons did not survive for 48 hr when cultured without this target-derived extract (Fig. $1 B$, open circles). The effect of CIPE was dose dependent, as lower concentrations $(0.3 \%)$ of CIPE resulted in intermediate levels of survival (Fig. $1 B$, solid squares). Therefore, in subsequent experiments, cell counts from $1.5 \%$ CIPE- and N2-incubated wells were included as control experiments.

\section{Coculture of intact choroid coats with dissociated neurons}

To test the possibility that the process of dissociating the choroid altered the surviving cell types or eliminated some cell types originally present in the tissue, dissociated CG neurons were plated directly on top of intact choroid sheets. After $2 \mathrm{~d}$, not only had the neurons survived but their processes had grown vigorously, creating striking parallel arrays of fibers covering the explants (Fig. 2A). Initially, the cell bodies of neurons applied to the intact choroid were distributed randomly on the tissue. However, after $5 \mathrm{~d}$ in culture, the cell bodies of the neurons had altered their distribution and aggregated into clusters while their processes had become fasciculated (Fig. $2 B$ ).

To determine whether axonal processes were actually making contact with smooth muscle cells within these choroidal coat explants, ultrastructural studies were performed. The gross anatomy of the intact embryonic choroid in organ culture differs from that of the in situ tissue, making ultrastructural distinction of the different cell types difficult. The blood vessels and lacunae that were clearly identifiable in the intact tissue are no longer visible. However, smooth muscle cells are relatively common in the explants and can be identified by the presence of thick and thin filaments (Fig. $3 A$, stars). This allows smooth muscle cells to be distinguished from fibroblasts and glia, which have only one kind of filament. However, smooth muscle cells in culture shift from a contractile to a synthetic mode (Thyberg et al., 1990), substantially decreasing the number of myofilaments, and most of these filaments in St 41-42 choroid are found at both poles of the cell (Meriney and Pilar, 1987). This makes ultrastructural identification of smooth muscle cells difficult, requiring serial sections to make this distinction in some cases. 


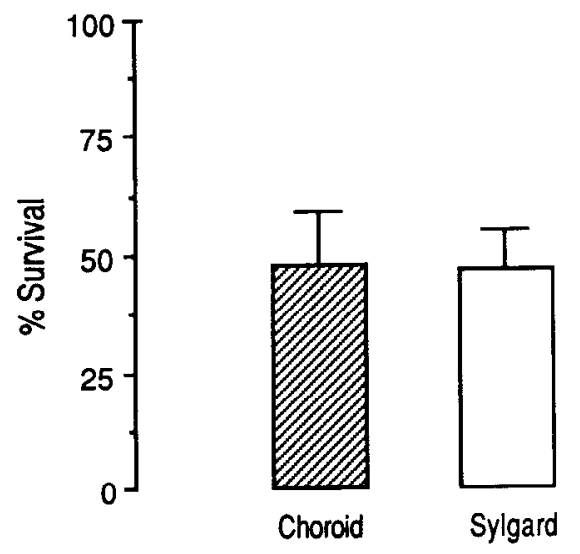

Figure 4. Survival of St $34 \mathrm{CG}$ neurons after $2.5 \mathrm{~d}$ of coculture with choroid explants (N2 medium). Hatched bar, neurons grown on the choroid explant; open bar, neurons growing outside the explant. Survival of neurons grown on Sylgard was comparable $(47 \% \pm 8)$ to that of neurons growing on top of the explant $(47 \% \pm 11)$.

Neurons grown on the explant extend processes that can be clearly identified as neuritic by their characteristic microtubules and round shape (Fig. $3 B$ ), and in many cases these axons (a) and varicosities $(\mathrm{v})$ were seen in close contact with the smooth muscle cells. However, for the reasons stated above, many observed neuronal contacts may have been on smooth muscle cells that could not be unambiguously identified in single sections.

\section{Survival of neurons on intact choroid explants}

Measurements of neuron survival on the intact choroid after $2.5 \mathrm{~d}$ in culture indicated that $48 \%$ of the neurons initially plated had survived (Fig. 4, hatched bar). However, after longer periods $(>2.5 \mathrm{~d})$ of coculture, accurate neuron counts proved difficult to obtain because the choroid explants had the tendency to shrink in culture. Consequently, although dissociated neurons clearly survived on choroid tissues, the exact cell count after $2-$ $3 \mathrm{~d}$ was unreliable. We observed that, in addition to being plated on the choroid substrate, many neurons were unintentionally plated on the untreated Sylgard-covered areas of the culture dishes. These cells, although not in contact with the target tissue, were bathed in the same medium and grew well under these conditions. Phase-contrast counts of these neurons indicated that at $2.5 \mathrm{~d}$ their survival was comparable to that of the neurons on top of the explants (approximately $48 \%$ of the initial count; compare Fig. 4: choroid, hatched bars; Sylgard, open bars). The presence or absence of pigment epithelium on the choroid sheets did not affect the survival of the ciliary neurons in either condition (data not shown).

\section{Cocultures of dissociated choroid with $C G$ neurons}

The above results demonstrate that explants of the choroid target tissues support the survival of the neurons in culture. These results conflict with earlier work by Creedon and Tuttle (1988), which showed that smooth muscle preparations, including dissociated cells from the choroid coat of the eye, did not promote survival of ciliary neurons in culture. In the following experiments, we examined the survival of the neurons using a cultured dissociated choroid preparation.

Confluent cultures of dissociated choroids from St 41 embryos supported the survival of approximately $40 \%$ of cocultured dissociated CG neurons in $\mathrm{N} 2$ media for at least $5 \mathrm{~d}$ (Fig. 5, solid

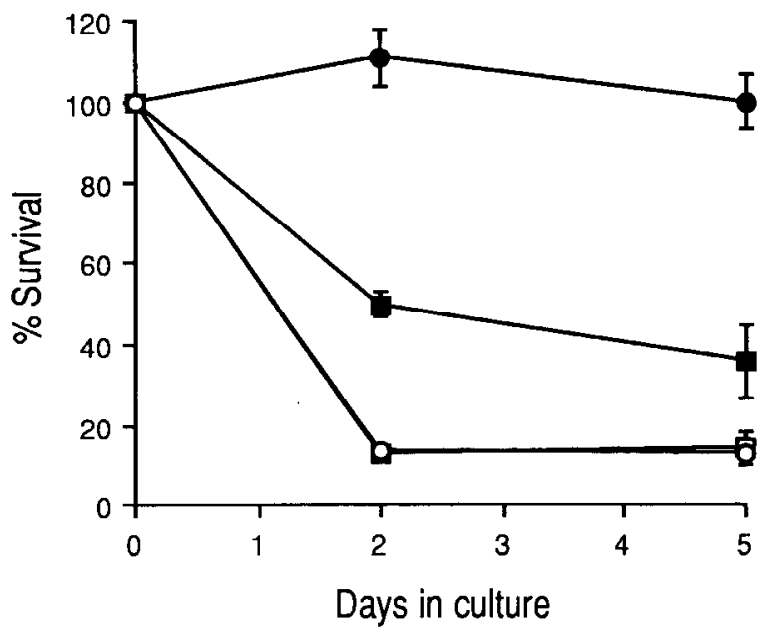

Figure 5. Survival of St $34 \mathrm{CG}$ neurons in coculture with dissociated choroid tissues. Cells from dissociated embryonic (St 41 ) choroid were grown to confluence in N2 plus 5\% CEE plus $10 \%$ horse serum (replication of Creedon and Tuttle, 1988, conditions; open squares) or in N2 plus 10\% FBS (without CEE; solid squares). Control cultures of neurons grown on P-Orn with CIPE (solid circles) or N2 alone (open circles). Note: without horse serum in the medium, half the neurons survived when cocultured with the dissociated choroid.

squares). To explain the difference between our results and those of Creedon and Tuttle (1988), we examined the difference in culture conditions between the two laboratories. In fact, when we duplicated their culture conditions by adding 5\% CEE and $10 \%$ horse serum to the culture medium (neither of which is present in N2 medium) during the attainment of confluence of the dissociated choroid, the dissociated ciliary neurons did not survive $48 \mathrm{hr}$ in culture (Fig. 5, open squares) and their survival is comparable to neurons grown in N2 alone (Fig. 5, open circles). This was true, even though the serum and extract were removed from the medium before the neurons were plated onto the dissociated choroid (see Materials and Methods). Therefore, this difference between culture media appears sufficient to account for the different results obtained by the two laboratories.

TEM also reveals the presence of smooth muscle cells in the dissociated choroid tissue (Fig. 6A) as in the explant (Fig. 3A). The cytoplasmic filaments with characteristic dense bodies seen (Fig. 6 $\mathrm{A}$, arrow) are diagnostic of smooth muscle. The neurons can be observed growing processes into dissociated choroid cells. Figure $6 B$ shows an axon bundle in cross section partially surrounded by a satellite cell. As shown in this plate, there is a close relationship between growing axons and dissociated cells. In some cases, as in Figure $6 C$, a growth cone $(\mathrm{gc})$ is seen 0.2 $\mu \mathrm{m}$ from a smooth muscle cell (sm), and varicosities containing both clear and dense-core vesicles (Fig. 6D) are seen close to smooth muscle cells $(\mathrm{sm})$, the presumptive target cells of these neurons. However, many of the contacts occur between growth cones (Fig. 7, gc) and smooth muscle (sm) cells that express the synthetic phenotype, which is characterized by extensive rough endoplasmic reticulum (RER) and a prominent Golgi complex (G).

\section{Diffusible factors from CCM support neuron survival}

To determine whether a diffusible factor(s) was involved in the survival of CG neurons in vitro, cocultures of neurons without direct contact with the target tissue (Fig. 4) were made by plating the neurons on Aclar coverslips and subsequently transferring 

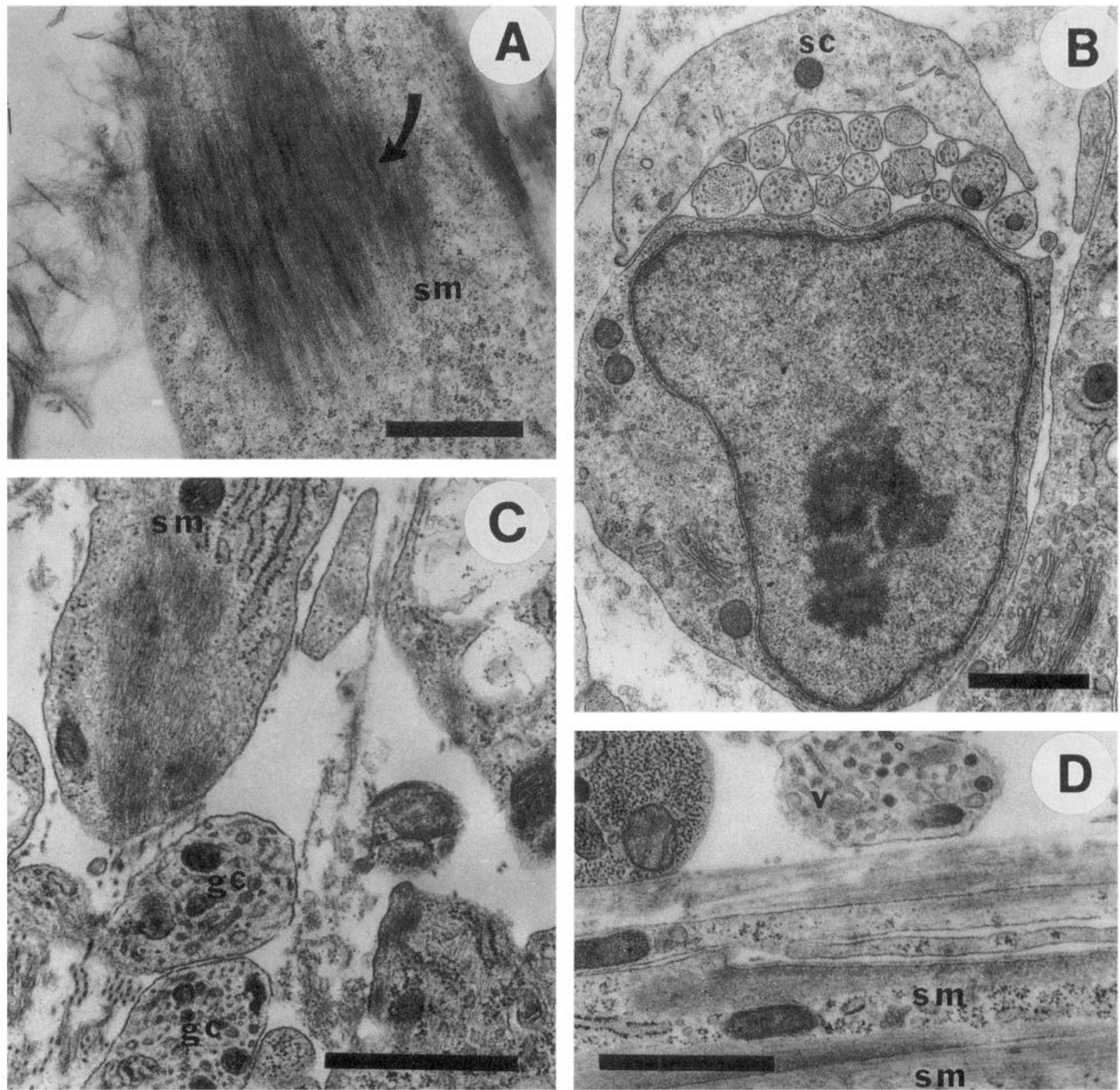

Figure 6. Transmission electron micrographs of neuron-dissociated choroid cocultures (N2 medium). Dissociated choroid cells were cultured for $5 \mathrm{~d}$, and then the dissociated neurons were seeded and cultured for an added $5 \mathrm{~d}$. A, Smooth muscle $(\mathrm{sm})$. Note presence of myofilaments and dense bodies (arrow). B, Bundled neuron processes surrounded by a satellite cell $(s c)$. $C$, Neuron growth cones $(g c)$ in close contact with a smooth muscle cell. This micrograph in which the smooth muscle cells have grown over the neuronal processes was selected from a partial serial reconstruction. $D$, A varicosity $(v)$ (containing clear and dense core vesicles) in close apposition to smooth muscle cells $(\mathrm{sm})$. Scale bars, $1 \mu \mathrm{m}$.

them to dishes containing intact choroid tissue in $\mathrm{N} 2$ media. Under these conditions (coculture without direct contact between the neurons and the choroid explant) $80-100 \%$ of the neurons survived for $2 \mathrm{~d}$ (Fig. 8: open squares, Aclar grown; solid squares, grown outside the explant). Neurons in N2 alone did not survive (Fig. 8, open circles). Therefore, it is clear that the target tissue, as well as medium conditioned by the target tissue, can support the survival of CG neurons. However, irrespective of the conditions used (intact, dissociated, or medium conditioned by choroid), not all of the neurons survive $3.5 \mathrm{~d}$ in culture (between $30 \%$ and $60 \%$; see Figs. $4,5,8$ ). In contrast, CIPE extract rescues all the neurons (Figs. $1 B ; 5$ and 8 , solid circles). There are at least two plausible explanations for the partial survival observed: the survival factor from the choroid could be specific for those neurons that innervate it (recall that the choroid is the natural target for only $50-60 \%$ of the ganglionic neurons; Landmesser and Pilar, 1974; Pilar et al., 1980), or, alternatively, the survival factor(s) produced by the choroid explants could be present in insufficient titer to support all the neurons. The following section describes experiments designed to distinguish between these two possibilities.

\section{Is there a choroid-derived trophic factor that is specific for choroid neurons?}

To test whether the survival factor from choroid tissue was specific for the choroid population of CG neurons, we selectively 


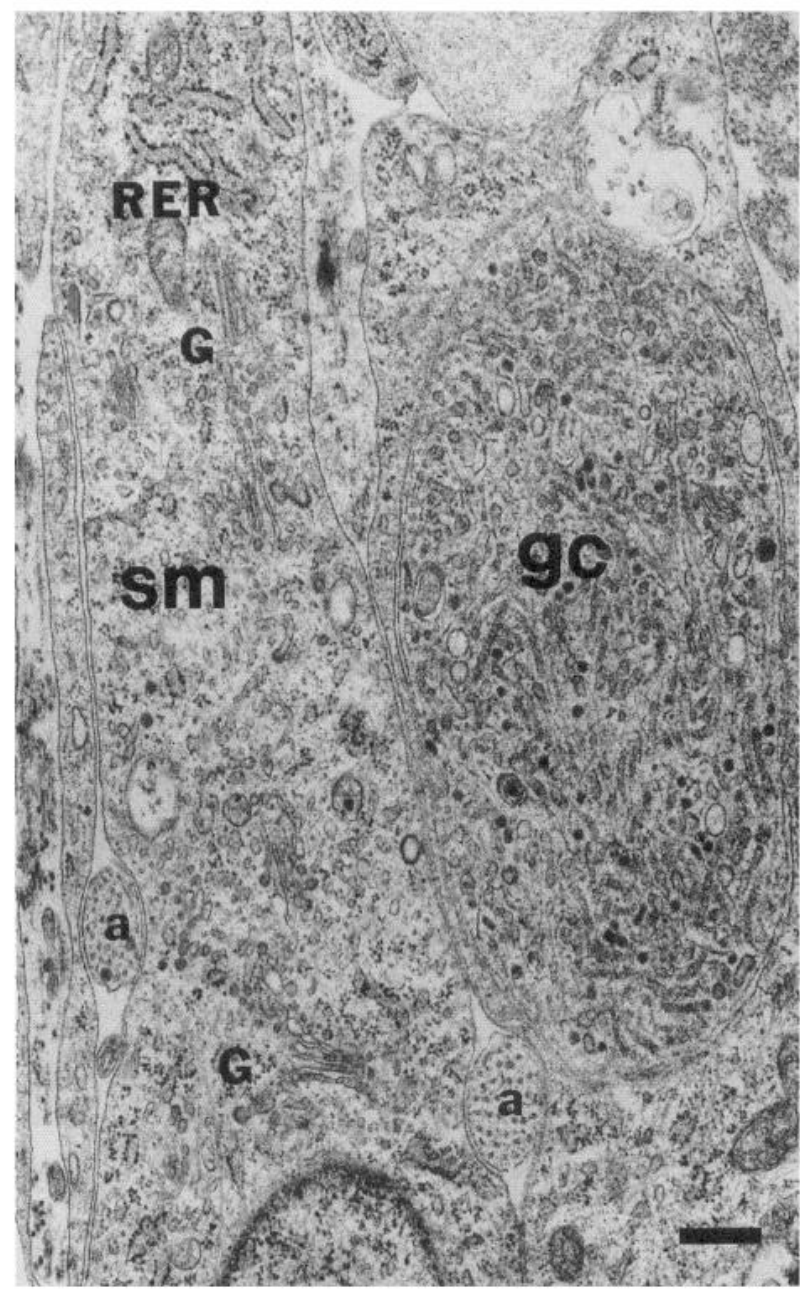

Figure 7. Transmission electron micrograph of a neuron-dissociated choroid coculture (same as Fig. 6). A central domain of the growth cone $(g c)$ is recognized by its abundance of organelles, clear and dense-core vesicles, and microtubules. This structure, surrounded by a unidentified cell, is in close proximity to a smooth muscle cell expressing the synthetic phenotype $(\mathrm{sm})$. This cell was followed in a partial serial reconstruction until a few myofilaments were identified (not shown). $R E R$, rough endoplasmic reticulum; $G$, Golgi system. Two axons ( $a$ ) are seen abutting the smooth muscle cell $(\mathrm{sm})$. Scale bar, $1 \mu \mathrm{m}$.

labeled the ciliary neurons and monitored survival of the dissociated neurons in the presence of CCM. Ciliary neurons were specifically labeled by injecting the lipophilic dye DiI (dissolved in $100 \% \mathrm{EtOH}$ ) into the stump of the ciliary nerve trunk. The DiI diffused retrogradely by the lipid moiety of the cell membrane to the cell bodies of the CG. Usually, the spread of the dye was restricted to the ciliary nerves, and thus to the ciliary neurons. However, occasionally the choroid neurons were inadvertently labeled and these were detected by visualizing the choroid nerves under epifluorescence (e.g., Fig. $9 D$, ch). These contaminated preparations were not used. In Figure 9, $A$ and $B$, the efficacy of this technique is demonstrated in a representative whole-mount of an injected CG observed under epifluorescence $(A)$ and phase optics $(B)$. When the two images are superimposed, as in Figure $9 B$ (dashed line indicates the borders of the fluorescent region), it is clear that the areas devoid of stain correspond to those containing choroid neurons. After labeling the neurons in this manner, the ganglia were dissociated and plated in P-Orn-coated plastic tissue culture wells. Figure

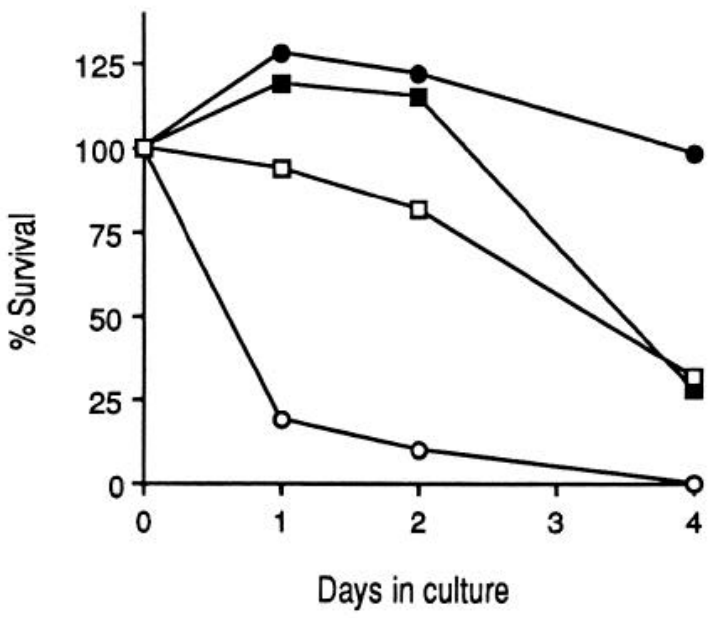

Figure 8. Survival of St $34 \mathrm{CG}$ neurons after $4 \mathrm{~d}$. Neurons were plated on Aclar coverslips and transferred to dishes containing choroid explants (open squares) or $\mathrm{N} 2$ medium was replaced with medium that had been "conditioned" by choroid ( $100 \%$ CCM) explants for 2-3 d (solid squares). Control wells of neurons growing in $1.5 \%$ CIPE (solid circles) and in N2 alone (open circles) are shown for comparison; $30 \%$ of the ciliary cells initially plated survived in the CCM. This experiment was illustrated because all conditions were from the same experiment. Each point represents the average counts of five different fields in two different wells in each condition. Notice that at day 1 and 2, the counts are higher than at $3 \mathrm{hr}$. This occasionally occurs because initially some neurons do not appear bright and therefore are not recognized.

10 shows the neurons under phase optics $(A$ and $C$; after 2 and $5 \mathrm{~d}$ ) and fluorescence ( $B$ and $D$; after 2 and $5 \mathrm{~d}$ ). Because it was not possible to label all the ciliary neurons (we estimate that approximately $60 \%$ of the ciliary population incorporated the dye), neuron survival is expressed in relative proportions of labeled (as counted under fluorescence) and total neurons [both labeled (Fig. 11, hatched bars) and unlabeled (open bars) neurons counted under phase optics] at $5 \mathrm{~d}$. Neurons grown in CIPE were used as controls. Although this concentration $(50 \% \mathrm{v} / \mathrm{v}$ diluted with N2) of CCM only supported the survival of $50 \%$ of the neurons originally plated, the same proportions of labeled and unlabeled cells were present at $5 \mathrm{~d}$ with both CIPE and CCM. Thus, the survival factors in CCM are not selective for choroid or ciliary neuron populations, even at submaximal concentrations.

\section{Effect of concentrated CCM on neuron survival}

Because we found no apparent specificity of the factor in CCM for the choroid neurons that innervate it, we next tested whether neuron survival could be increased by concentrating the conditioned medium. The survival of neurons grown in concentrated CCM was assayed 2 and $4 \mathrm{~d}$ after plating by counting and the results are shown in Figure 12. Two concentrations were tested, $2.5 \times$ (open bar) and $5 \times$ (hatched bar). After $2 \mathrm{~d}$, both concentrations resulted in 100\% survival, but after $4 \mathrm{~d} \mathrm{100 \%}$ survival was only maintained with the higher concentration. The experiments indicate that the factor(s) provided by the choroid has a molecular weight of more than $10 \mathrm{kDa}$ and is capable of supporting the survival of both populations of CG neurons.

\section{Characterization of cell type responsible for survival activity}

The target tissue formed by the choroid is complex, including vascular smooth muscle, vascular endothelium, fibroblasts, epithelium, nerve, and nonvascular smooth muscle. Much of this 

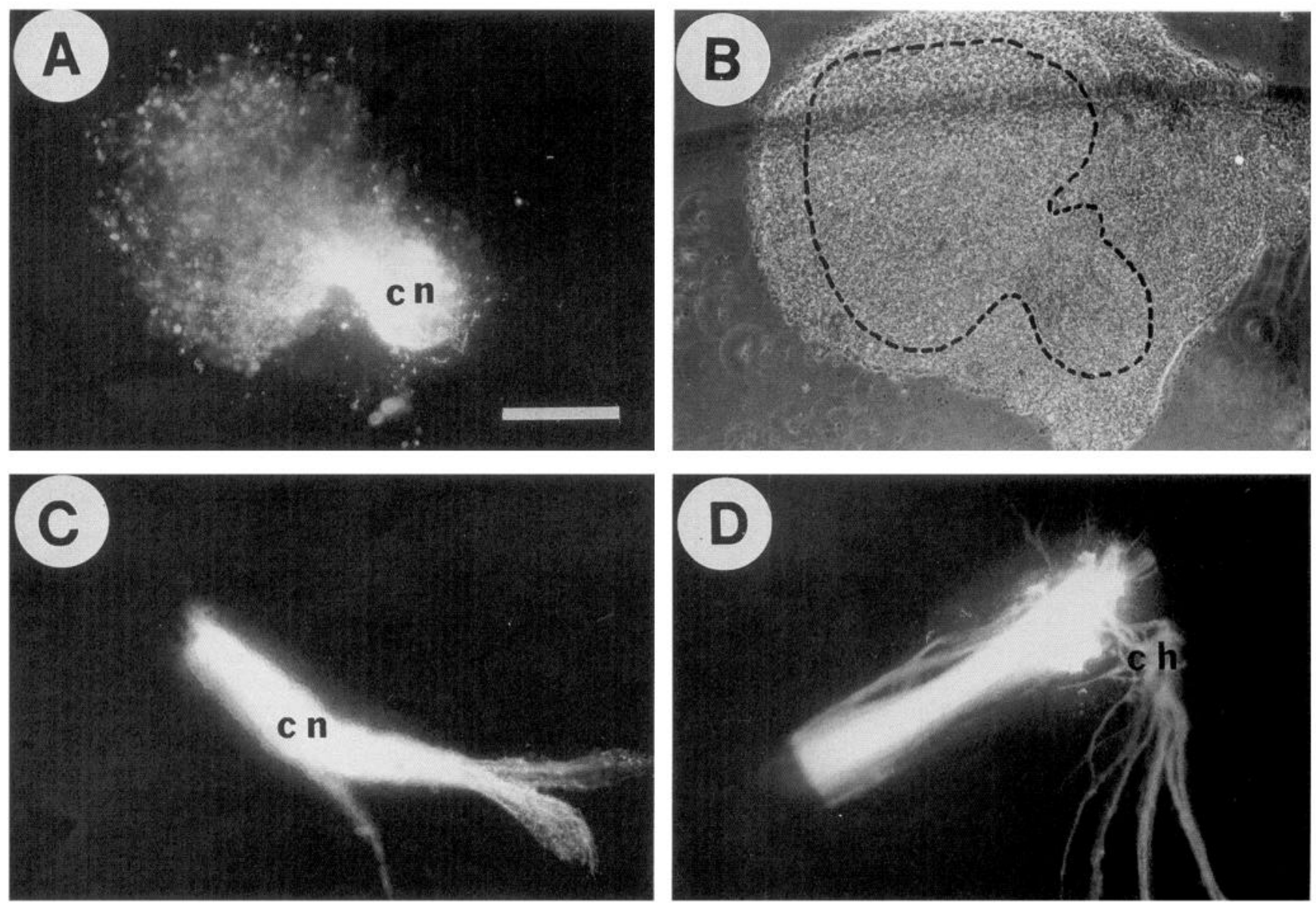

Figure 9. Dil-injected CG. A, Epifluorescent image of ganglion showing labeled ciliary neurons following injection into the ciliary nerves ( $c n$ ). $B$, Phase-contrast micrograph of same field as in $A$, with field $A$ superimposed on the image. $C$, Fluorescence micrograph showing successfully injected ciliary nerve $(c n)$. D, Example of choroid nerve "contamination" by DiI $(c h)$. The ganglion associated with this micrograph was discarded. Scale bar, $500 \mu \mathrm{m}$.

complexity is retained in cultured choroid, although dedifferentiation (Chamley-Campbell et al., 1979) of smooth muscle cells may occur. Smooth muscle cells shift from the contractile to the synthetic phenotype (Fig. 7; Thyberg et al., 1990), making the distinction between fibroblasts and smooth muscle cells more difficult. In fact, during in vivo development, the identification of smooth muscle was laborious because the smooth muscle cells expressed the secretory phenotype during the naturally occurring cell death period (Meriney and Pilar, 1987; Thyberg et al., 1990). By coculturing the neurons with simple cellular preparations, we have identified the cell types that provide trophic support for the CG neurons.

The avian amnion was used as a source of embryonic smooth muscle to test the ability of this tissue to support the survival of ciliary neurons in culture. Conditioned medium from the amnion supports dissociated ciliary neurons in vitro. The effect is dose dependent such that at $5 \mathrm{~d} 10 \%$ amnion-conditioned medium (ACM) and 50\% ACM (v/v, diluted with N2) support $31 \%$ and $72 \%$ of the neurons originally plated (Fig. 13, open squares, solid squares, respectively). It is particularly noteworthy that this tissue is composed solely of smooth muscle and a simple epithelium, and is uninnervated, avascular, and devoid of fibroblasts (Romanoff, 1960; Bowers and Dahm, 1992). Thus, even a simple smooth muscle-containing tissue is capable of supporting dissociated ciliary neurons.
We used three different approaches to test for fibroblast involvement in the survival activity of CCM. First, confluent primary fibroblast cultures were used as a substrate for dissociated neurons in culture. After 3 d CG neurons were no longer observed in either the experimental (N2 medium) or the control $(1.5 \%$ CIPE) wells. During this time, the fibroblasts overran the culture wells; therefore, it is possible that mechanical detachment of the neurons from the growing fibroblasts was a factor in the death of the neurons. Similarly, in control neuron-fibroblast cocultures with $1.5 \%$ CIPE, only a few neurons survived after $3 \mathrm{~d}$. In other experiments, neurons were cocultured with fibroblasts whose ability to divide had been reduced by repeated passages. After $2 \mathrm{~d}$ only $25 \%$ of the neurons cocultured with fibroblasts in N2 medium survived when compared with control cocultures grown in N2 with $1.5 \%$ CIPE. Although these neurons survived throughout the $5 \mathrm{~d}$ culture period, none had processes. Second, fibroblasts from the mouse cell line 3T3 were tested as a substrate for St $35 \mathrm{CG}$ neurons. The neurons were counted after 2 and $5 \mathrm{~d}$ of coculture with the fibroblasts. After $48 \mathrm{hr}$ in $\mathrm{N} 2$ medium, fewer than $5 \%$ of the neurons initially plated were still alive. Finally, the ability of fibroblasts to release a soluble survival factor was tested by culturing neurons in primary fibroblast-conditioned medium (50\% and $100 \%)$. In this experiment, all the neurons died within $2 \mathrm{~d}$. 

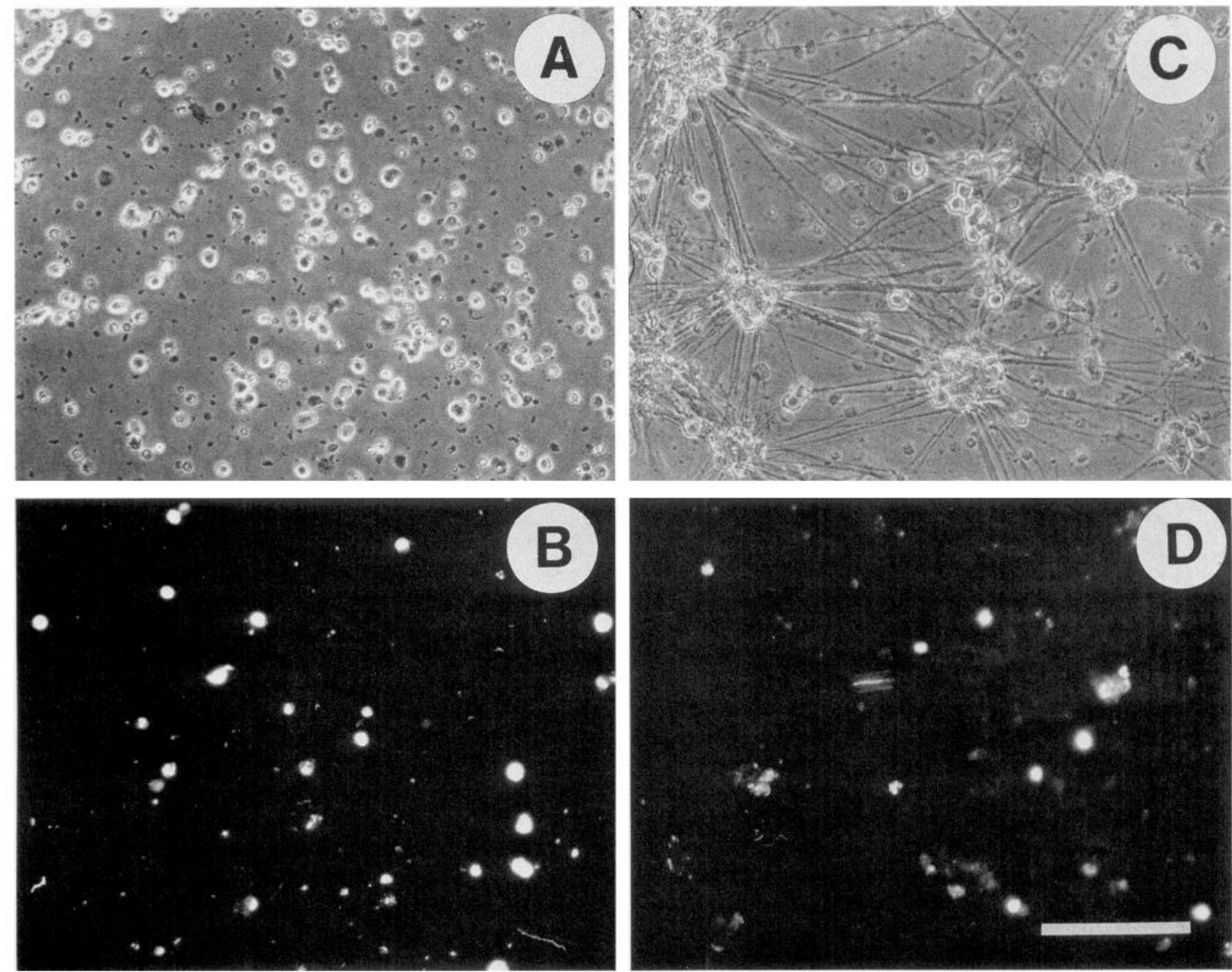

Figure 10. Dissociated Dil-injected CG neurons were grown in 50\% CCM. $A$ and $B$, after $2 \mathrm{~d}$ in culture; $C$ and $D$, after $5 \mathrm{~d}$ in culture. $A$ and $C$, phase contrast; $B$ and $D$, fluorescent optics. Prints are from the same fields. Note the vigorous growth at $5 \mathrm{~d}$. Scale bar, $100 \mu \mathrm{m}$.

\section{Discussion}

The purpose of this work is to test the general hypothesis that target tissues support the survival of the neurons that innervate them during development. This general principle has been demonstrated both in vitro and in vivo and is especially well documented for motoneurons innervating striated muscle targets (Pilar et al., 1988). This principle was not tested in a smooth muscle system until recently, when Creedon and Tuttle (1988) demonstrated that one target of the CG neuron, vascular smooth muscle (and indeed the choroid coat of the eye itself), lacked the ability to support the neurons in vitro. The CG comprises two populations of motoneurons, one innervating the smooth muscle of the choroid coat vasculature and the other innervating the striated muscle of the iris and ciliary body. The fact that the smooth muscle target (the choroid) failed to support ciliary neuron survival led these investigators to suggest the intriguing possibility that neuron survival is regulated differently in neurons innervating smooth muscle and striated muscle targets.

Originally, our intent was to determine whether the process of dissociating the choroid, as Creedon and Tuttle (1988) had done, rendered this tissue incapable of supporting neuron survival in vitro. Instead, we found that dissociated choroid cells were as effective as intact choroid tissue "explants" in supporting the survival of CG neurons. EM studies of choroidneuron cocultures revealed axons and varicosities intermixed with other cellular elements of the explant. Moreover, we identified smooth muscle cells in the explant and in a few instances we visualized close contact (junctional regions) between terminal axons or varicosities and these cells. In cocultures of dissociated choroid we also observed a few close interactions between neurons and putative target cells. Interestingly, some of these contacts were made between growth cones closely juxtaposed (between 20 and $300 \mathrm{~nm}$ ) with cellular elements, some of which displayed ultrastructural similarities (organelle distribution, filaments, and associated dense bodies) to smooth muscle cells. However, the rarity of close contacts observed between nerve and muscle cells, both in explants and in dissociated culture, suggests that many neurons are not making direct contact with these cells.

In coculture experiments such as those described here, it is difficult to separate the influence of target contact from an effect of conditioned medium on survival because the medium invariably becomes conditioned with a variety of substances leaked, secreted, or released from the cellular elements in the dish. This occurs in cocultures of neurons with striated muscle, where 


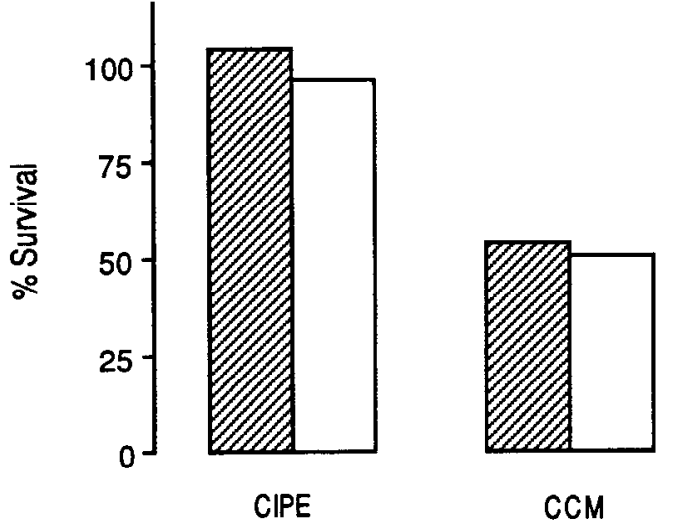

Figure 11. Survival of St 34 CG neurons in $50 \%$ CCM as compared to CIPE, after $5 \mathrm{~d}$ in culture. Ciliary neurons (injected with DiI; hatched bars) are compared to ciliary and choroid neurons (open bars). The ratio of labeled ciliary neurons to labeled choroid and ciliary cells was not changed during the $5 \mathrm{~d}$ when neurons were growing in CCM. Data are from two experiments. Notice that although the survival of both populations of the labeled and unlabeled cells are unchanged, the total number of neurons that survive in CCM is $50 \%$ at $5 \mathrm{~d}$.

direct nerve-muscle contact is not the only factor implicated in survival (Nishi and Berg 1977, 1979). Indeed, contact with muscle cells (White and Bennett, 1978) and muscle fragments (Tuttle, 1983) as well as exposure (without contact) to conditioned media from different kinds of tissues (striated and cardiac muscle; Collins and Lee, 1982; Vaca et al., 1985; Watters and Hendry, 1987) effectively support neurons in culture. Clearly, in many culture experiments it is difficult to assess the relevance of the observations to what is actually supporting the neurons in vivo. In fact, our data have established that the complex anatomical interaction that occurs in vivo between neurons and their target cells is not necessary for their survival in vitro since all the neurons are rescued with CCM. Fibroblasts are probably not a source of trophic factor since only $25 \%$ of those neurons plated on a substrate of fibroblasts survive. One explanation for this partial neuronal survival is that the dying fibroblasts are a source of fibroblast growth factor (FGF; Creedon and Tuttle, 1990). This is consistent with previous observations of similar neuronal survival of ciliary cells cocultured with fibroblast

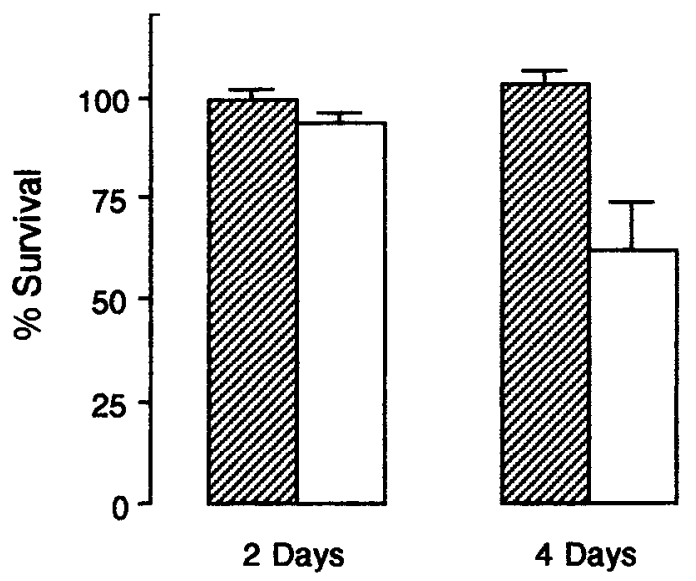

Figure 12. Neuron survival on concentrated CCM after 2 and $4 \mathrm{~d}$ in vitro. CG cells were counted in $5 \times \mathrm{CCM}$ (hatched bars) or $2.5 \times \mathrm{CCM}$ (open bars). The error bars for $5 \mathrm{~d}$ are the range of the values $(n=2)$.

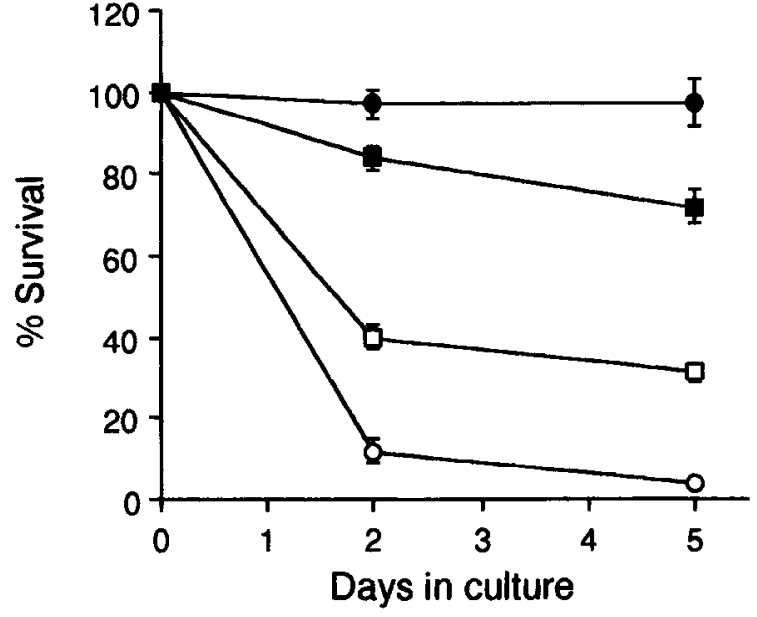

Figure 13. Survival of CG neurons grown in ACM. The survivalpromoting activity of this simple tissue is attributed to smooth muscle or epithelial cells (or a combination of the two). Solid circles, control CIPE; open circles, N2; solid squares, $50 \%$ ACM; open squares, $10 \%$ $\mathrm{ACM}$

membrane remnants (Nishi and Berg, 1981; Creedon and Tuttle, 1990).

Finally, although avian amnion contains only three layers of cells and two cell types, smooth muscle and epithelium, (Romanoff, 1960; Bowers and Dahm, 1992), ACM also rescues all the dissociated neurons. The anatomical simplicity of the avian amnion, coupled with the fact that pigment epithelium is unnecessary for trophic activity, suggests that smooth muscle cells may be sufficient as a source of trophic factor.

Our findings demonstrate that culturing choroid tissue in the presence of horse serum and embryo extracts actually prevents the choroid from later sustaining ciliary neurons. In contrast, dissociated choroids grown in defined N2 medium (without horse serum) maintain their survival activity. Toxic effects of horse serum on cultured motoneurons have been documented by several laboratories (Dohrman et al., 1986; Tanaka, 1987; Garcia et al., 1992). We therefore attribute Creedon and Tuttle's inability to demonstrate trophic activity of dissociated choroid to the use of a medium containing horse serum that compromised the neuron survival-promoting activity of these cells. The tissue culture conditions we used may favor the expression of a smooth muscle phenotype that supports neuron survival. For example, it is well established that dissociation and culture of smooth muscle cells, from a variety of sources, result in a phenotypic transformation of the muscle that is associated with a loss of contractility (Chamley-Campbell et al., 1979; Thyberg et al., 1990). Of interest, perhaps, to investigators using in vitro techniques is the fact that this transformation can be modulated by using different culture conditions (Hedin et al., 1988). Of special relevance to the present study are recent data indicating that N2 medium maintains contractility of cultured smooth muscle more effectively than other media (Bowers and Dahm, 1993). Moreover, the addition of serum to N2 medium causes loss of contractility in both intact and dissociated amniotic smooth muscle, while $\mathrm{N} 2$ media without serum maintained the contractile phenotype (Bowers, 1989; Bowers and Dahm, 1993). It is possible, therefore, that the sensitivity of smooth muscle phenotype to culture conditions plays an important role in the ability of choroid to provide trophic support for $C G$ neurons.

The results of the back-fill experiments demonstrate that the 
trophic activity from the choroid target of the $C G$ is not specific for neurons that innervate it. This important issue was addressed directly by injecting the neurons innervating the ciliary body (striated muscle target) with DiI, dissociating the ganglia, and dispersing the neurons in medium containing 50\% $(\mathrm{v} / \mathrm{v}$ diluted with N2) CCM. That equal proportions of labcled and unlabcled neurons survived indicates that the factor(s) was affecting the two different neuron populations equally.

The tendency for the neurons on intact and dissociated choroid to fasciculate may reflect a relative lack of affinity for the choroid tissue (Rutishauser et al., 1978; Rutishauser and Edelman, 1980). However, the nature of the specific molecular cues responsible for the dramatic orientation of nerve fibers in young cocultures of intact choroid (see Fig. $2 A$ ) and their apparent change with time are intriguing. It has been shown, for example, that embryonic CG neurons gradually lose lamininbinding integrin heterodimers between days 8 and 14 (Tomaselli and Reichardt, 1988). This loss may contribute to the rearrangement of the neurons and their processes that we have observed. It should be noted that the intact choroid has highly patterned distributions of blood vessels (Meriney and Pilar, 1987).

The biochemical nature of the factor(s) described in this article remains unknown. Several molecules with neurotrophic activity for $C G$ neurons have been isolated from a variety of sources, including chick eye (Barbin et al., 1984), rat sciatic nerve (Manthorpe et al., 1986), bovine cardiac muscle (Watters and Hendry, 1987), and rabbit sciatic nerve (Lin et al., 1989). The most wellknown trophically active component present in the choroid explants is ciliary neurotrophic factor (CNTF), a molecule of approximately $20 \mathrm{kDa}$ that is apparently responsible for a significant fraction of the trophic activity of eye extracts (Barbin et al., 1984). Recently, Nishi and collaborators purified and cloned a CNTF-related molecule from chick eye (Eckenstein et al., 1990; Leung et al., 1992). This molecule, called GPA (growthpromoting activity), may be chick CNTF. GPA can support the survival of dissociated ciliary neurons in culture, is induced in the chick cyc during normal ciliary neuronal cell death, is expressed in dissociated smooth muscle from choroid, and is released from cells transfected with GPA cDNA. However, CNTF is not the only molecule known to rescue CG neurons in culture. FGF has also been shown to support ciliary neurons in vitro (Unsicker et al., 1987; Giulian et al., 1988; Haynes, 1988) and in vivo (Dreyer et al., 1989). The highly vascular choroid coat contains endothelial cells and smooth muscle cells, both of which are known to be sources of FGF (Speir et al., 1991). Although recent work has suggested that neither CNTF nor FGF rescues ciliary neurons in vivo (Oppenheim et al., 1991, 1992), GPA has not yet been tested in this regard. Smooth muscle cells also secrete a variety of other growth-promoting agents, including platelet-derived growth factor (PDGF) (Majesky et al., 1990), but nothing is known about the effects of PDGF in promoting neuronal survival.

The cvidence presented in this article, although not conclusive, supports the hypothesis of the secretion of the soluble trophic factor from choroid smooth muscle cells. However, the possibility that factors with trophic activity are released into the extracellular milieu as a result of cell death or injury cannot be discounted (McNeil et al., 1989). In the present study, and indeed in virtually all conditioned medium studies, the distinction between secretion of a factor versus the release of a factor from wounded or dying cells is potentially quite important. While cell injury-induced "release" may have physiological relevance in vivo for certain growth (Eckenstein et al., 1991) and immune factors that respond to injury (Auron et al., 1984), it is not the putative mechanism for trophic interactions during neural development.

In summary, our observations demonstrate that the choroid coat of the eye, a target of the CG with smooth muscle and endothelial/epithelial cells, supports the survival of all of the ganglion's neurons in a defined medium. The trophic activity of conditioned medium, explants, and dissociated choroid is consistent with other reports of trophic activity associated with extracts of various structures in the eye (Adler et al., 1979; Eckenstein et al., 1990; Leung et al., 1992). It should be noted that, although others have used the word "choroid" to denote a particular extract, their protocol included the choroid, ciliary body, pigmented epithelium, and sclera (Adler et al., 1979). Because both intact and dissociated choroids provide trophic support for CG neurons, an indirect argument can be made that cell injury and release of trophic substances is not the only factor involved in the present results. However, we need techniques to distinguish rigorously between secretion and constant low levels of release due to injury or cell death in vitro. The possibility exists that cell injury with its postulated leakage represents an alternative pathway for the release of trophic substances in culture. If trophic factors are indeed released or secreted from smooth muscle or epithelial/endothelial cells, it will be important to determine what mechanisms are involved.

\section{References}

Adler R, Landa K, Manthorpe M, Varon S (1979) Cholinergic neuronotrophic factors. II. Intraocular distribution of trophic activity for ciliary neurons. Science 204:1434-1436.

Auron PE, Webb AC, Rosenwasser LJ, Mucci SF, Rich A, Wolff SM, Dinarello CA (1984) Nuclcotide scquence of human monocyte interleukin 1 precursor cDNA. Proc Natl Acad Sci USA 81:7907-7911.

Barbin G, Manthorpe M, Varon S (1984) Purification of the chick eye ciliary neuronotrophic factor. J Neurochem 43:1468-1478.

Bennett MR, Nurcombe V (1979) The survival and development of cholinergic neurons on skeletal muscle conditioned media. Brain Res 173:543-548.

Bottenstein JE (1983) Defined media for dissociated neural cultures. In: Current methods in cellular neurobiology, Vol 4, pp 107-130. New York: Wiley.

Bowers CW (1989) Expression of functional neurotransmitter receptors in an uninnervated tissue: avian amnion. Cell Tissue Res 258: $409-415$.

Bowers CW, Dahm LM (1992) Extracellular matrix regulates smooth muscle responses to substance P. Proc Natl Acad Sci USA 89:81308134.

Bowers CW, Dahm LM (1993) Maintenance of contractility in dissociated smooth muscle: low density cultures in a defined medium. Am J Physiol 264 Cell Physiol 33:C229-C236.

Chamley-Campbell J, Campbell GR, Ross R (1979) The smooth muscle cell in culture. Physiol Rev 59:1-61.

Collins F, Lee MR (1982) A reversible developmental change in the ability of ciliary ganglion neurons to extend neurites in culture. $J$ Neurosci 2:424-430.

Cowan WM, Fawcett JW, O'Leary DDM, Stanfield BB (1984) Regressive events in neurogenesis. Science 225:1258-1265.

Creedon DJ, Tuttle JB (1988) Cultured smooth muscle targets lack survival activity for ciliary ganglion neurons. J Neurosci 8:31003110.

Creedon DJ, Tuttle JB (1990) Soluble and membrane-bound factors together account for target dependence of cultured parasympathetic neurons. Dev Brain Res 56:281-289.

Dahm LM, Landmesser LT (1988) The regulation of intramuscular nerve branching during normal development and following activity blockade. Dev Biol 130:621-644.

Dohrman U, Edgar D, Sendtner M, Thoenen H (1986) Muscle-derived 
factors that support survival and promote fiber outgrowth from embryonic chick spinal motor neurons in culture. Dev Biol 118:209221.

Dreyer D, Lagrange A, Grothe C, Unsicker K (1989) Basic fibroblast growth factor prevents ontogenic neuron death in vivo. Neurosci Lett 99:35-38.

Eckenstein FP, Esch F, Holbert T, Blacher RW, Nishi R (1990) Purification and characterization of a trophic factor for embryonic peripheral neurons: comparison with fibroblast growth factors. Neuron 4:623-631.

Eckenstein FP, Shipley GD, Nishi R (1991) Acidic and basic fibroblast growth factors in the nervous system: distribution and differential alteration of levels after injury of central versus peripheral nerve. $J$ Neurosci 11:412-419.

Garcia JE Jr, Nonner D, Ross D, Barrett JN (1992) Neurotoxic components in normal serum. Exp Neurol 118:309-316.

Giulian D, Vaca K, Johnson B (1988) Secreted peptides as regulators of neuron-glia and glia-glia interactions in the developing nervous system. Neuroscience 21:487-500.

Hamburger V, Hamilton HL (1951) A series of normal stages in the development of the chick embryo. J Morphol 88:49-92.

Hamburger V, Oppenheim RW (1982) Naturally occurring neuronal death in vertebrates. Neurosci Comm 1:39-55.

Haynes LW (1988) Fibroblast (heparin-binding) growing factors in neuronal development and repair. Mol Neurobiol 2:263-289.

Hedin U, Bottger BA, Forsberg E, Johansson S, Thyberg J (1988) Diverse effects of fibronectin and laminin on phenotypic properties of cultured arterial smooth muscle cells. J Cell Biol 107:307-319.

Honig MG, Hume RI (1986) Fluorescent carbocyanine dyes allow living neurons of identified origin to be studied in long-term cultures. J Cell Biol 103:171-187.

Landmesser L, Pilar G (1974) Synaptic transmission and cell death during normal ganglionic development. J Physiol (Lond) 241:737749.

Leung DW, Parent AS, Cachianes G, Esch F, Coulombe JN, Nickolics, K, Eckenstein FP, Nishi R (1992) Cloning, expression during development and evidence for release of a trophic factor for ciliary ganglion ncurons. Neuron 8:1045-1053.

Lin L-F, Mismer D, Lile JD, Armes LG, Butler ET III, Vann JL, Collins F (1989) Purification, cloning, and expression of ciliary neurotrophic factor. Science 246:1023-1025.

Majesky MW, Daemens MJAP, Schwartz SM (1990) $\alpha$-Adrenergic stimulation of platelet-derived growth factor A-chain gene expression in rat aorta. J Biol Chem 265:1082-1088.

Manthorpe M, Skaper S, Adler R, Landa K, Varon S (1980) Cholinergic neuronotrophic factors: fractionation properties of an extract from selected chick embryonic eye tissues. J Neurochem 34:69-75.

Manthorpe M, Skaper SD, Williams LR, Varon S (1986) Purification of adult rat sciatic nerve ciliary neuronotrophic factor. Brain Res 367 : 282-286.

Marwitt R, Pilar G, Weakly JN (1971) Characterization of two cell populations in avian ciliary ganglia. Brain Res 25:317-334.

McNeil PL, Muthukrishnan L, Warder E, D'Amore PA (1989) Growth factors are released by mechanically wounded endothelial cells. J Cell Biol 109:811-822.

Meriney SD, Pilar G (1987) Cholinergic innervation of the smooth muscle cells in the choroid coat of the eye and its development. $J$ Neurosci 7:3827-3839.

Meriney SD, Pilar G, Ogawa M, Nunez R (1987) Differential neuronal survival in the avian ciliary ganglion after chronic acetylcholine receptor blockade. J Neurosci 7:3840-3849.

Nishi R, Berg DK (1977) Dissociated ciliary ganglion neurons in vitro: survival and synapse formation. Proc Natl Acad Sci USA 74:51715175 .
Nishi R, Berg DK (1979) Survival and development of ciliary neurons grown alone in cell culture. Nature 277:232-234.

Nishi R, Berg DK (1981) Two components from eye tissue that differentially stimulate the growth and development of ciliary ganglion neurons in cell culture. J Neurosci 1:505-513

Oppenheim RW, Prevette D, Yin QW, Collins F, McDonald J (1991) Control of embryonic motoneuron survival in vivo by ciliary neurotrophic factor. Science 251:1616-1618.

Oppenheim RW, Prevette D, Fuller F (1992) The lack of effect of basic and acidic fibroblast growth factors on the naturally occurring death of neurons in the chick embryo. J Neurosci 12:2726-2734.

Paul J (1970) Cell and tissue culture, 4th ed, p 78. Baltimore: Williams and Wilkins.

Pilar G, Landmesser L, Burstein L (1980) Competition for survival among developing ganglion cells. J Neurophysiol 43:233-254.

Pilar GR, Meriney SD, Gray DB (1988) Trophic effects of muscle on nerve cell survival and development. In: Nerve-muscle cell trophic communication (Fernandez HL, Donoso JA, eds), pp 173-198. Boca Raton, FL: CRC.

komanoff AL (1960) The avian embryo: structural and functional development, p 192. New York: Macmillan.

Rutishauser U, Edelman GM (1980) Effects of fasciculation on the outgrowth of neurites from spinal ganglia in culture. J Cell Biol 87: 370-378.

Rutishauser U, Gall W, Edelman G (1978) Adhesion among neural cells of the chick embryo. IV. Role of the cell surface molecule CAM in the formation of neurite bundles in cultures of spinal ganglia. $J$ Cell Biol 79:382-393.

Skaper SD, Selak I, Manthorpe M, Varon S (1984) Chemically defined requirements for the survival of cultured 8 -day chick embryo ciliary ganglion neurons. Brain Res 302:281-290.

Speir E, Sasse J, Shrivastav S, Casscells W (1991) Culture-induced increase in acidic and basic fibroblast growth factor activities and their association with the nuclei of vascular endothelial and smooth muscle cells. J Cell Physiol 147:362-373.

Tanaka H (1987) Chronic application of curare does not increase the level of motoneuron survival-promoting activity in limb muscle extracts during the naturally occurring motoneuron cell death period. Dev Biol 124:347-357.

Thyberg J, Hedin U, Sjolund M, Palmberg L, Bottger B (1990) Regulation of differentiated properties and proliferation of arterial smooth muscle cells. Arteriosclerosis 10:966-990.

Tomaselli KJ, Reichardt LF (1988) Peripheral motoneuron interactions with laminin and Schwann cell-derived neurite-promoting molecules: developmental regulation of laminin receptor function. Neuroscience 21:275-285.

Tuttle JB (1983) Interaction with membrane remnants of target myotubes maintains transmitter sensitivity of cultured neurons. Science 220:977-979

Unsicker K, Reichert-Preibsch H, Schmidt R, Pettman B, Labourdette G, Sensenbrenner M (1987) Astroglial and fibroblast growth factor have neurotrophic functions for cultured peripheral and central nervous system neurons. Proc Natl Acad Sci 84:5459-5463.

Vaca K, McManaman J, Bursztajn S, Appel SH (1985) Differential morphologic effects of two fractions from fetal calf muscle on cultured chick ciliary ganglion cells. Dev Brain Res 19:37-46.

Watters DJ, Hendry IA (1987) Purification of a ciliary neurotrophic factor from bovine heart. J Neurochem 49:705-713.

Wentzek LAF, Bowers CW, Oliva ED, Pilar G (1989) Intact smooth muscle preparations secrete trophic factors that support dissociated ciliary neurons in vitro. J Neurosci Abstr 15:309.

White WB, Bennett MR (1978) The survival and development of cholinergic neurons in the presence of striated muscle 'in vitro.' Brain Res 159:379-384. 